\title{
Central venous catheter-related thrombosis in intensive care patients - incidence and risk factors: A prospective observational study
}

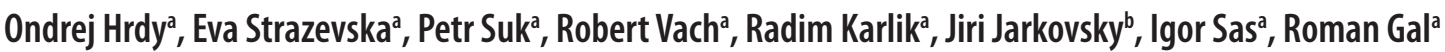

\begin{abstract}
Background. One of the complications associated with central venous catheter (CVC) placement is catheter related deep vein thrombosis (CR-DVT). However a literature search revealed little evidence of this recognised complication. The primary aim of this study was to establish the incidence rate and risk factors for the development of CR-DVT in our critically ill adult patients.

Methods. All critically ill adult patients admitted to the medical-surgical ICU with CVC inserted were included in this observational prospective study. After catheter removal we performed duplex ultrasound examination to assess the patency of the vein and establish if CR-DVT was present.

Results. A total number of 308 catheters met the inclusion criteria of which 198 were included in the statistical analysis. The CVC was inserted into a subclavian vein (SCV) in 139 (70\%) cases and in an internal jugular vein (IJV) in 59 (30\%) cases. The 28 -day mortality rate was $14.1 \%$. We found CR-DVT during duplex ultrasound examination in 47 (26\%) of all cases. 33 (70\%) of the CR-DVT were diagnosed in the IJV and 14 (30\%) in the SCV. The risk factors for the development of CR-DVT we identified included cannulation of the IJV and the use of treatment dose of LMWH. The effect of CR-DVT on 28-day mortality was not statistically significant.

Conclusion. The risk factors for CR-DVT we identified were IJV as a site for CVC cannulation and the use of therapeutic anticoagulation prior to cannulation. Our recommendation would be preferential cannulation of a subclavian vein as opposed to an internal jugular vein in order to reduce the risk of CR-DVT.
\end{abstract}

Key words: central venous catheter, deep vein thrombosis, risk factors, critical care

Received: February 7, 2017; Accepted: July 12, 2017; Available online: August 24, 2017 https://doi.org/10.5507/bp.2017.034

${ }^{a}$ Department of Anaesthesiology and Intensive Care Medicine, University Hospital Brno and Faculty of Medicine, Masaryk University, Brno, Czech Republic

'Institute of Biostatistics and Analyses, Faculty of Medicine, Masaryk University, Brno, Czech Republic

Corresponding author: Ondrej Hrdy, e-mail: ondrej.hrdy@fnbrno.cz

\section{INTRODUCTION}

Central venous catheter (CVC) insertion is an integral part of the management of critically ill patients in intensive care units (ICU). These catheters are placed for the administration of hypertonic solutions, catecholamines, nutritional solutions, insertion of temporary transvenous pacemakers, and for hemodynamic monitoring ${ }^{1}$. Up to $64 \%$ of critically ill patients will require CVC cannulation $^{2}$. One of the complications related to the central venous cannulation is DVT (ref. ${ }^{3}$ ) which can lead to pulmonary embolism (ref. $\left.{ }^{4}\right)$.

However, on searching the on-line literature (MEDLINE database in last 10 years) using keywords "central venous catheter" and "deep vein thrombosis" we could find no article concerning catheter related deep vein thrombosis (CR-DVT) in adult critically ill patients in intensive care units.

There are studies in MEDLINE dated earlier but none of these is focused on critically ill adult ICU patients.

In the view of the progress and development of intensive care medicine, development of DVT prophylaxis algorithms and newer catheter material, we decided to perform a study focused on this topic. The primary aim of this study was to establish the incidence rate of CR-
DVT and risk factors for the development of CR-DVT in critically ill adult patients. The secondary aim was to establish the impact of CR-DVT on the mortality rates of critically ill patients.

\section{METHODS}

This prospective, monocentric, observational study was approved by The Ethics Research Committee of Faculty Hospital Brno. Informed consent was not requested.

It was an observational study and there were no changes made to the treatment of the patients based on its findings. If signs of DVT were diagnosed we followed the guidelines for management of patients with suspected DVT $\left(\right.$ ref. $\left.^{5,6}\right)$.

All patients admitted to our ICU from November 2013 to November 2014 were enrolled after fulfilling the inclusion criteria and in the absence of any exclusion criteria (Table 1). If there were more than one CVC inserted in a patient we enrolled each as a separate case.

We did not dictate the choice of catheter insertion site and catheter type. Local guidelines for the insertion of CVC were followed. An anteroposterior chest X-ray 
Table 1. Inclusion and exclusion criteria.

\begin{tabular}{ll}
\hline Inclusion criteria & Exlusion criteria \\
\hline $\begin{array}{l}\text { Admition to ICU from the 1st of November 2013 } \\
\text { to the 1st of November 2014 }\end{array}$ & previous cannulation of analysed vessels \\
Age $\geq 18$ years & previous thrombosis in the analysed vessels \\
CVC inserted $\geq 48$ hours & previous trauma of the analysed vessels \\
Cannulation of internal jugular vein or subclavian vein & trauma of the collar bone on the site of CVC insertion \\
- & $\begin{array}{l}\text { insertion of a vascath, pulmonary artery catheter or sheath for } \\
\text { temporary pacing }\end{array}$ \\
\hline
\end{tabular}

Table 2. Risk factors of CR-DVT identified in literature.

\begin{tabular}{lcl}
\hline Risk factor & Analysed in our study & Comment \\
\hline Age & Yes & - \\
Gender & Yes & - \\
Cancer & Yes & - \\
Acquired hypercoagulable states & No & not able to diagnose in all patients \\
Inherited coagulation disorders & No & only few patient in several years admited \\
High platelet count & Yes & - \\
Barbiturates & No & not used on our ICU \\
Propofol & Yes & - \\
Parenteral nutrition & Yes & - \\
Lack of therapeutic anticoagulation & Yes & - \\
$>10$ packed red blood cell & Yes & - \\
Number of lumina & Yes & - \\
CVC material & No & all catheter made from polyuretane \\
Difficult insertion & No & not able to identify from documentation in all patients \\
Position of the CVC tip & Yes & - \\
Catheter related sepsis & No & not able to diagnose in all cases \\
Catheter-days & Yes & - \\
\hline
\end{tabular}

was used to confirm the CVC position. We applied the method for CVC correct placement assessment described by Luciani ${ }^{7}$. Catheter tip outside of the segment 1 and 2 in the radiograph was considered as a diagnostic criterion for malposition.

The diagnosis of CR-DVT was established using duplex ultrasound imaging. The imaging was performed either immediately or up to $24 \mathrm{~h}$ after catheter removal. A linear probe with the frequency of $3-9 \mathrm{MHz}$ was used for the imaging. The diagnosis of CR-DVT was established in accordance with a procedure protocol ${ }^{6,8}$. The patients were examined in a supine position with a mildly abducted upper limb. Imaging of the internal jugular vein (IJV) and subclavian vein ( $\mathrm{SCV}$ ) was performed at the site of cannulation. We used the B mode in longitudinal (long axis) plane, transversal (short axis) plane and duplex imaging with compression of the evaluated vein.

The diagnosis was confirmed either directly in the B-mode or indirectly using signs of thrombosis.

The extent of the thrombosis was graded as wall changes, incomplete or complete obstruction of the vein lumen.

The ultrasound findings were recorded in designated study form. Based on the literature review we identified potential risk factors of CR-DVT (Table 2).

Standard descriptive statistics were used to summarise the data with absolute and relative frequencies for categorical variables and median plus $5-95^{\text {th }}$ percentile or means plus SD. Statistical significance of differences between groups of patients was tested using Fisher's exact test for categorical data and Mann-Whitney $U$ test for continuous data.

Logistic regression was adopted for the identification of risk factors for CR-DVT and the impact of CR-DVT on 28-days mortality. Statistical analysis was computed using SPSS 23.0.0.0 (IBM Corporation, 2015).

\section{RESULTS}

There were 795 patients admitted to our ICU during the study period. Of these patients, we enrolled 278. There were 333 CVC included from which 25 CVC were excluded using exclusion criteria (Table 3 ). We also had to exclude 110 catheters for impracticability to perform an ultrasound examination. The most frequent result of 
Table 3. Exclusion criteria.

\begin{tabular}{lc}
\hline Criterion & Number of cases $(\mathrm{n}=25)$ \\
\hline Previous cannulation of analysed vessels & 7 \\
Previous thrombosis in the analysed vessels & 0 \\
Previous trauma of the analysed vessels & 0 \\
Trauma of the collar bone on the site of CVC insertion & 14 \\
Insertion of a vascath, pulmonary artery catheter or sheath for temporary pacing & 4 \\
\hline
\end{tabular}

Table 4. Results of ultrasound imaging.

\begin{tabular}{lc}
\hline Ultrasound finding & Number of cases $(\mathrm{n}=198)$ \\
\hline No signs of CR-DVT & $151(76 \%)$ \\
Wall changes & $15(8 \%)$ \\
Incomplete obstruction of vein & $32(16 \%)$ \\
Complete obstruction of vein & $0(0 \%)$ \\
\hline
\end{tabular}

pathological ultrasound imaging was incomplete obstruction of the vein (Table 4). Statistical analysis was calculated for 198 (64.3\%) of CVC.

Characteristics of the study population are summarized in Table 5. Based on ultrasound examination the CR-DVT was diagnosed in $47(24 \%)$ of cases. The signs and symptoms of CR-DVT were observed in 2 cases. The risk factors for CR-DVT identified were IJV cannulation and therapeutic anticoagulation at the time of CVC insertion (Table 6). The effect of CR-DVT on 28-day mortality was not statistically significant (Table 7).

\section{DISCUSSION}

Central vein cannulation is a common procedure in the ICU setting. Deep vein thrombosis is one of the complications described during central vein cannulation ${ }^{1,3}$.

In our study we diagnosed thrombosis following CVC extraction in $47(24 \%)$ patients, which is in agreement with other studies concerning the topic ${ }^{9,10}$.

Risk of CR-DVT is higher when CVC is inserted in IJV than in SCV (ref. ${ }^{11-13}$ ). We confirmed CR-DVT as the

Table 5. Characteristics of study population.

\begin{tabular}{|c|c|c|c|c|c|}
\hline \multirow{2}{*}{ Characteristic $^{1}$} & & \multirow{2}{*}{$\begin{array}{c}\text { Total } \\
(n=198)\end{array}$} & \multicolumn{2}{|c|}{ Deep vein thrombosis: } & \multirow{2}{*}{$P^{2}$} \\
\hline & & & No $(n=151)$ & Yes $(n=47)$ & \\
\hline Age & & $\begin{array}{c}58.0 \\
(20.0 ; 83.0)\end{array}$ & $\begin{array}{c}57.0 \\
(19.0 ; 82.0)\end{array}$ & $\begin{array}{c}63.0 \\
(20.0 ; 85.0)\end{array}$ & 0.121 \\
\hline Gender & $\begin{array}{l}\text { Male } \\
\text { Female }\end{array}$ & $\begin{array}{c}135(68.2 \%) \\
63(31.8 \%)\end{array}$ & $\begin{array}{c}107(70.9 \%) \\
44(29.1 \%)\end{array}$ & $\begin{array}{l}28(59.6 \%) \\
19(40.4 \%)\end{array}$ & 0.155 \\
\hline Infection & & $52(26.3 \%)$ & $35(23.2 \%)$ & $17(36.2 \%)$ & 0.089 \\
\hline Cancer & & $25(12.6 \%)$ & $19(12.6 \%)$ & $6(12.8 \%)$ & 0.999 \\
\hline Platelet count & & $\begin{array}{c}200.0 \\
(77.0 ; 491.0)\end{array}$ & $\begin{array}{c}208.0 \\
(77.0 ; 454.0)\end{array}$ & $\begin{array}{c}166.5 \\
(78.0 ; 580.0)\end{array}$ & 0.328 \\
\hline Prophylactic anticoagulation & $\begin{array}{l}\text { LMWH } \\
\text { Other } \\
\text { No }\end{array}$ & $\begin{array}{c}71(35.9 \%) \\
1(0.5 \%) \\
126(63.6 \%)\end{array}$ & $\begin{array}{c}53(35.1 \%) \\
0(0.0 \%) \\
98(64.9 \%)\end{array}$ & $\begin{array}{c}18(38.3 \%) \\
1(2.1 \%) \\
28(59.6 \%)\end{array}$ & 0.261 \\
\hline Therapeutic anticoagulation & $\begin{array}{l}\text { LMWH } \\
\text { Other } \\
\text { No }\end{array}$ & $\begin{array}{c}1(0.5 \%) \\
5(2.5 \%) \\
192(97.0 \%)\end{array}$ & $\begin{array}{c}0(0.0 \%) \\
2(1.3 \%) \\
149(98.7 \%)\end{array}$ & $\begin{array}{c}1(2.1 \%) \\
3(6.4 \%) \\
43(91.5 \%)\end{array}$ & 0.029 \\
\hline Site of insertion & $\begin{array}{l}\text { Internal jugular vein } \\
\text { Subclavian vein }\end{array}$ & $\begin{array}{c}59(29.8 \%) \\
139(70.2 \%)\end{array}$ & $\begin{array}{c}26(17.2 \%) \\
125(82.8 \%)\end{array}$ & $\begin{array}{l}33(70.2 \%) \\
14(29.8 \%)\end{array}$ & $<0.001$ \\
\hline Number of CVC lumens & $\begin{array}{l}2 \\
3 \\
4\end{array}$ & $\begin{array}{c}2(1.0 \%) \\
191(96.5 \%) \\
5(2.5 \%)\end{array}$ & $\begin{array}{c}1(0.7 \%) \\
145(96.0 \%) \\
5(3.3 \%)\end{array}$ & $\begin{array}{c}1(2.1 \%) \\
46(97.9 \%) \\
0(0.0 \%)\end{array}$ & 0.324 \\
\hline Medication & $\begin{array}{l}\text { Propofol } \\
\text { Parenteral nutriton } \\
\text { Transfusion therapy }\end{array}$ & $\begin{array}{l}122(62.9 \%) \\
24(12.1 \%) \\
69(34.8 \%)\end{array}$ & $\begin{array}{l}92(62.2 \%) \\
17(11.3 \%) \\
52(34.4 \%)\end{array}$ & $\begin{array}{c}30(65.2 \%) \\
7(14.9 \%) \\
17(36.2 \%)\end{array}$ & $\begin{array}{l}0.731 \\
0.609 \\
0.862\end{array}$ \\
\hline Catheter-days & & $\begin{array}{c}9.0 \\
(4.0 ; 16.0)\end{array}$ & $\begin{array}{c}9.0 \\
(4.0 ; 16.0)\end{array}$ & $\begin{array}{c}9.0 \\
(4.0 ; 18.0)\end{array}$ & 0.587 \\
\hline Catheter position & $\begin{array}{l}\text { Correct } \\
\text { Malposition }\end{array}$ & $\begin{array}{c}155(78.3 \%) \\
43(21.7 \%)\end{array}$ & $\begin{array}{l}121(80.1 \%) \\
30(19.9 \%)\end{array}$ & $\begin{array}{l}34(72.3 \%) \\
13(27.7 \%)\end{array}$ & 0.311 \\
\hline
\end{tabular}

\footnotetext{
${ }^{1}$ absolute and relative frequency for categorical data, median with 5-95 percentile for continuous data

${ }^{2}$ Fisher's exact test for categorical data analysis. Mann-Whitney U test for continuous data.
} 
Table 6. Risk factors for catheter related deep vein thrombosis.

\begin{tabular}{llcc}
\hline Charakteristic & & OR $(95 \% \mathrm{CI})$ & $P^{I}$ \\
\hline Age & one-unit increase & $1.013(0.996 ; 1.031)$ & 0.134 \\
\hline Gender & Male & ref. & 0.149 \\
\hline Infection & Female & $1.650(0.836 ; 3.258)$ & 0.080 \\
\hline Cancer & & $1.878(0.928 ; 3.801)$ & 0,974 \\
\hline Platelet count & one-unit increase & $1,017(0,381 ; 2,716)$ & 0.781 \\
\hline Prophylactic anticoagulation & LMWH/other & $1.000(0.998 ; 1.002)$ & 0.508 \\
\hline Therapeutic anticoagulation & & $1.255(0.641 ; 2.456)$ & $\mathbf{0 . 0 2 8}$ \\
\hline Site of insertion & Internal jugular vein & $6.930(1.227 ; 39.128)$ & $<\mathbf{0 . 0 0 1}$ \\
Internal jugular vein & Subclavian vein & ref. & 0.407 \\
\hline Number of CVC lumens & 2 & $11.332(5.329 ; 24.099)$ & 0.708 \\
& $\geq 3$ & ref. & 0.506 \\
\hline Medication & Propofol & $0.307(0.019 ; 5.000)$ & 0.828 \\
\hline Catheter-days & Parenteral nutriton & $1.141(0.571 ; 2.279)$ & 0.867 \\
\hline Catheter position & Transfusions & $1.379(0.534 ; 3.561)$ & 0.260 \\
\hline
\end{tabular}

${ }^{1}$ calculation based on Logistic regression

Table 7. Catheter related deep vein thrombosis as a risk factor of 28-day mortality.

\begin{tabular}{llccc}
\hline & \multicolumn{2}{c}{ 28-day mortality } & OR (95\% CI) & $P^{2}$ \\
Deep vein thrombosis $^{1}$ & No $(\mathrm{n}=170)$ & Yes $(\mathrm{n}=28)$ & ref. & \\
\hline No $(\mathrm{n}=151)$ & $127(84.1 \%)$ & $24(15.9 \%)$ & $0.492(0.162 ; 1.499)$ & 0.212 \\
Yes $(\mathrm{n}=47)$ & $43(91.5 \%)$ & $4(8.5 \%)$ & \\
\hline
\end{tabular}

${ }^{1}$ absolute and relative frequency for categorical data

${ }^{2}$ calculation based on Logistic regression

more frequent complication following IJV cannulation (56\%) as opposed to SCV cannulation (10\%).

In our opinion, this disproportion could be explained by the lower tendency of SCV to collapse due to anatomic relations. Direct damage of the vessel wall by the catheter is more likely in the collapsed vessel. Another contributing factor to higher rate of CR-DVT in cannulation of IJV could be greater mechanical damage of the vessel wall related to catheter movements during motion of the head and neck.

We observed that patients who require therapeutic anticoagulation because of venous thromboembolism (VTE) prior to cannulation showed a higher incidence of CR-DVT.

The reason for this may be the hypercoagulable state for which the anticoagulation therapy was indicated and the consequent need for modification of LMWH treatment after admission to ICU because of the risk of haemorrhage. The treatment with LMWH was returned when the risk of bleeding was considered lower than the risk of VTE.

Although LMWH is used for prophylaxis of VTE its effect on the incidence of CR-DVT is ambiguous ${ }^{6,12}$. In our study there was no demonstrated effect of prophylactic LMWH treatment on the incidence of CR-DVT.
Malposition of the catheter tip is a risk factor for CRDVT (ref. ${ }^{7,14,15}$ ). We did not confirm the relationship of the catheter tip position and CR-DVT. The reason could be the number of catheter-days and type of catheter inserted. In these studies long-term implantable catheters were studied.

Previous studies have shown that patients who do not receive lipids and propofol have a higher risk of CR-DVT (ref., ${ }^{9,16}$ ). We did not observe that in our study. Patients who receive parenteral nutrition have a higher risk of CRDVT ( ref. $^{17}$ ). The reason could be its effect on coagulation. Parenteral nutrition induces the activation of the platelet membrane glycoprotein and could contribute to a higher rate of CR-DVT ( ref. $^{18}$ ). We did not demonstrate this in our study. The reason could be the different number of catheter-days. The mean number of catheter-days was 9.5 whereas in the above named study the mean number of catheter-days in excess of 30 days.

Results of studies on dealing with the effect of transfusion therapy and the presence of infection on the frequency of CR-DVT are ambiguous ${ }^{9,16,19-21}$. In our study, we did not observe any relation between transfusion therapy, the presence of infection and a higher incidence of CR-DVT.

The effect of platelet count on the incidence of CRDVT has been investigated in several studies ${ }^{9,22}$. We found 
no statistically significant difference in platelet count between patients with or without CR-DVT.

\section{CONCLUSION}

CR-DVT occurred in $24 \%$ of our critically ill patients following cannulation of either the IJV or SCV. As risk factors for development of CR-DVT we identified cannulation of IJV and the use of therapeutic anticoagulation prior to cannulation.

There was no impact of age, gender, infection, cancer, platelet count, prophylactic anticoagulation, number of CVC lumens, propofol, parenteral nutrition, transfusion, number of catheter-days or catheter tip position on the incidence of CR-DVT. We found no effect of CR-DVT on 28-day mortality. We would recommend preferential cannulation of SCV as opposed to IJV in order to reduce the risk of CR-DVT.

\section{ABBREVIATIONS}

CR-DVT, Catheter related deep vein thrombosis; CVC, Central venous catheter; DVT, Deep vein thrombosis; ICU, Intensive care unit; IJV, Internal jugular vein; LMWH, Low molecular weight heparin; SCV, Subclavian vein; TU RBC, Transfusion units of red blood cells; VTE, Venous thromboembolism.

Author contributions: All authors: study design, protocol preparing, data interpretation, final approval; $\mathrm{OH}, \mathrm{ES}$ : study investigation; OH, ES, PS, RK: ultrasound examinations; JJ: statistical analyses.

Conflict of interest statement: None declared.

\section{REFERENCES}

1. Taylor RW, Palagiri AV. Central venous catheterization. Crit Care Med 2007:35:1390-6.

2. Vincent JL, Bihari DJ, Suter PM, Bruining HA, White J, NicolasChanoin MH, Wolff M, Spencer RC, Hemmer M. The prevalence of nosocomial infection in intensive care units in Europe. Results of the European Prevalence of Infection in Intensive Care (EPIC) Study. JAMA 1995;274:639-44.

3. Polderman KH, Girbes ARJ. Central venous catheter use. Part 1. Mechanical complications. Intensive Care Med 2002;28:1-17.

4. Lechner D, Wiener C, Weltermann A, Eischer L, Eichinger S, Kyrle PA. Comparison between idiopathic deep vein thrombosis ofthe upper and lower extremity regarding risk factors and recurrence. JThromb Haemost 2008;6:1269-74.
5. Kahn SR, Lim W, Dunn AS, Cushman M, Dentali F, AkI EA, Cook DJ, Balekian AA, Klein RC, Le H, Schulman S, Murad MH. Prevention of VTE in Nonsurgical Patients. Chest 2012;141 Suppl 2:e195S-e226S.

6. Chin EE, Zimmerman PT, Grant EG. Sonographic evaluation of upper extremity deep venous thrombosis. J Ultrasound Med 2005;24:82938.

7. Luciani A, Clement O, Halimi P, Goudot D, Portier F, Bassot V, Luciani JA, Avan P, Frija G, Bonfils P. Catheter-related upper extremity deep venous thrombosis in cancer patients: a prospective study based on Doppler US. Radiology 2001;220:655-60.

8. American College of Radiology (ACR), American Institute of Ultrasound in Medicine (AIUM), Society of Radiologists in Ultrasound (SRU). Practice guideline for the performance of peripheral venous ultrasound examinations. J Ultrasound Med 2011;30:143-50.

9. Timsit JF, Farkas JC, Boyer JM, Martin JB, Misset B, Renaud B, Carlet J. Central vein catheter-related thrombosis in intensive care petients: incidence, risk factors, and relationship with catheter.related sepsis. Chest 1998;114:207-13.

10. van Rooden CJ, Tesselaar MET, Osanto S, Rosendaal FR, Huisman MV. Deep vein thrombosis associated with central venous catheters - a review. J Thromb Haemost 2005;3:2409-19.

11. Wu X, Studer W, Skarvan K, Seeberger MD. High incidence of intravenous thrombi after short-term central venous cathetrisationm of the internal jugular vein. J Clin Anaest 1999;11:482-5.

12. Malinoski $D$, Ewing $T$, Bhakta $A$, Schutz $R$, Imayanagita $B$, Casas $T$, Woo N, Margulies D, Barrios C, Lekawa M, Chung R, Bukur M, Kong A. Which Central Venous Catheters Have the Highest Rate of CatheterAssociated Deep Venous Thrombosis: A Prospective Analysis of 2,128 Catheter Days in the Surgical Intensive Care Unit. J Trauma Acute Care Surg 2013;74:454-60;61-2

13. Parienti JJ, Mongardon N, Mégarbane B, Mira JP, Kalfon P, Gros A, Marqué $S$, Thuong $M$, Pottier V, Ramakers $M$, Savary $B$, Seguin A, Valette X, Terzi N, Sauneuf B, Cattoir V, Mermel LA, du Cheyron D. Intravascular complications of central venous catheterization by insertion site. N Engl J Med 2015;373:1220-9.

14. Rosovsky RP, Kuter DJ. Catheter-related thrombosis in cancer patients: pathophysiology, diagnosis, and management. Hematol Oncol Clin North Am 2005;19:183-202.

15. Freytes CO. Thromboembolic complications related to central venous access catheters in cancer patients. Semin Thromb Hemost 2007;33:389-96.

16. Gentile A, Petit L, Masson F, Cottenceau V, Bertrand-Barat J, Freyburger G, Pinaquy C, Léger A, Cochard JF, Sztark F. Subclavian central venous catheter-related thrombosis in trauma patients: incidence, risk factors and influence of polyurethane type. Crit Care 2013;17:R103.

17. Kucher N. Clinical practice: deep-vein thrombosis of the upper extremities. N Engl J Med 2011;64:861-9.

18. Li Y, Li Z, Wan M, Xia X, Wang J, Li J. Activation of platelet membrane glycoprotein induced by parenteral nutrition: a preliminary report. JParenter Enteral Nutr 2011;35:511-15.

19. Rogers FB, Cipolle MD, Velmahos G, Rozycki G, Luchette FA. Practice management guidelines for the prevention of venous thromboembolism in trauma patients: the EAST practice management guidelines work group. J Trauma 2002;53:142-64.

20. Levi M, Keller TT, van Gorp E, ten Cate H. Infection and inflammation and the coagulation system. Cardiovascular Research 2003;60:26-39.

21. Ito T. PAMPs and DAMPs as triggers for DIC. Journal of Intensive Care 2014;2:67.

22. Joynt GM, Kew J, Gomersall CD, Leung VY, Liu EK. Deep venous thrombosis caused by femoral venous catheters in critically ill adult patients. Chest 2000;117:178-83. 